NASA Technical Memorandum 107304

IECEC-96424

\title{
An Advanced Photovoltaic Array Regulator Module
}

Robert M. Button

Lewis Research Center

Cleveland, Ohio

Prepared for the

31st Intersociety Energy Conversion Engineering Conference cosponsored by IEEE, AIChE, ANS, SAE, AIAA, and ASME Washington, D.C., August 11-16, 1996

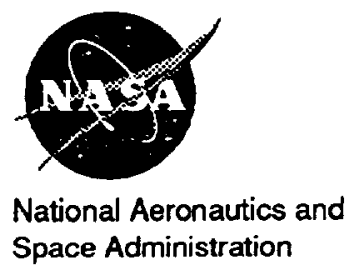





\title{
AN ADVANCED PHOTOVOLTAIC ARRAY REGULATOR MODULE
}

\author{
Robert M. Button \\ National Aeronautics and Space Administration \\ Lewis Research Center \\ 21000 Brookpark Rd. \\ Cleveland, Ohio 44135 \\ (216) $433-8010$
}

\begin{abstract}
Current trends in satellite design are focused on developing small, reliable, and inexpensive spacecraft. To that end, a modular power management and distribution system is proposed which will help transition the aerospace industry towards an assembly line approach to building spacecraft. The modular system is based on an innovative DC voltage boost converter called the Series Connected Boost Unit (SCBU). The SCBU uses any isolating DC-DC converter and adds a unique series connection. This simple modification provides the SCBU topology with many advantages over existing boost converters. Efficiencies of $94-98 \%$, power densities above $1,000 \mathrm{~W} / \mathrm{kg}$, and inherent fault tolerance are just a few of the characteristics presented. Limitations of the SCBU technology are presented, and it is shown that the SCBU makes an ideal photovoltaic array regulator. A set of photovoltaic power system requirements are presented that can be applied to almost any low Earth orbit satellite. Finally, a modular design based on the series connected boost unit is outlined and functional descriptions of the components are given.
\end{abstract}

\section{INTRODUCTION}

In the past few years the spacecraft industry has shifted their sights away from large, expensive, decade-long projects towards small and inexpensive satellites. Low cost spacecraft that can be developed in less than 3 years are being considered the wave of the future in space science and communications. Many new communication systems consist of a constellation of several small, inexpensive satellites. In fact several companies are planning to fly constellations of 66 to 840 satellites to provide global communications. It is clear that the satellite industry must transition from building custom satellites towards an "assembly line" approach.

Many of these small spacecraft will have missions in and around low Earth orbit (LEO). Although there are slight variations due to different payload needs, most LEO satellites have very similar electric power system requirements. These requirements can be generalized as: managing battery charge rates by regulating the solar array output, protecting the satellite from load and system faults, and reporting status information to the spacecraft computer.

These similarities in the power system requirements can lead directly to similar power systems. However, most satellite power systems are still designed from scratch using many unique parts. The cost of custom-made space electronics is extremely high, and the long development times account for a large portion of the total spacecraft cost and schedule.

A modular power system designed around a generalized LEO mission could have a big impact on new satellite programs. First, modular parts are relatively inexpensive since they are mass produced. Low recurring costs are a must when planning an 800 satellite constellation. Second, spacecraft development is reduced to simply selecting the right number of pre-engineered "modules" to meet the mission requirements, thus reducing the development times and associated costs.

A new DC-DC power processing technology is showing great promise in bringing small, efficient, and inexpensive converters to a modular power system architecture. This new technology is being demonstrated in a flight experiment aboard the Small Spacecraft Technology Initiative (SSTD) Lewis spacecraft (Baez, et. al, 1996).

\section{THE SERIES CONNECTED BOOST UNIT}

The Series Connected Boost Unit (SCBU) is not a new DCDC converter topology. Instead, it is a unique interconnect topology which makes novel use of an isolating DC-DC converter. The "series connection", or interconnect, topology is introduced below followed by an analysis of the SCBU's benefits over existing boost converters.

\section{SCBU Topology}

The Series Connected Boost Unit is based on the principle of biasing an isolated voltage source on top of another source. Figure 1 shows the very simple series connection of two isolated DC sources. The two power supplies in Figure 1 add together to provide $28 \mathrm{Vdc}$ to a $2.8 \Omega$ load. The load current, $\mathrm{I}=10 \mathrm{~A}$, is the same in each source since they are connected in series. 


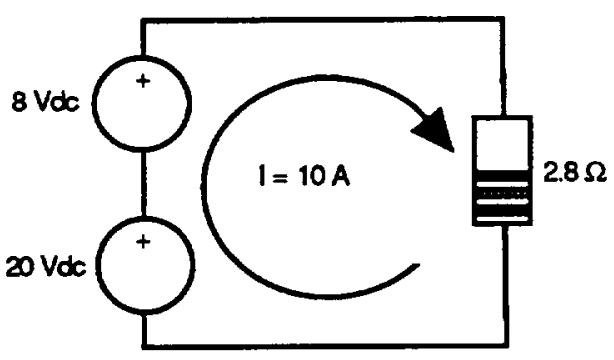

FIGURE 1 - DC SUPPLIES CONNECTED IN SERIES

To demonstrate how this series connection is used in the SCBU, the 8 Vdc power supply is replaced by a DC-DC converter as shown in Figure 2 . This converter is characterized as having an input voltage range of $16-32 \mathrm{Vdc}$, an average efficiency of $85 \%$, an output voltage of $8 \mathrm{Vdc}$, and an output current rating of $10 \mathrm{~A}$. This DC-DC converter is powered by a separate 20 Vdc source.

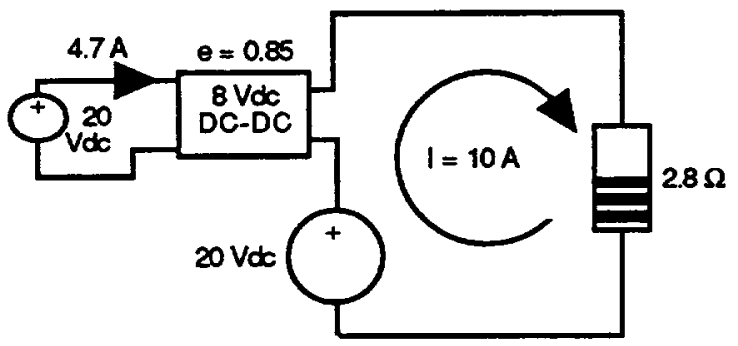

\section{FIGURE 2 - SUBSTMUTE ISOLATED DC-DC CONVERTER}

The DC-DC converter input current can be calculated using the output power and efficiency:

$$
\begin{gathered}
P_{\text {in }}=\frac{P_{d c}}{e}=\frac{8 \mathrm{~V} \cdot 10 \mathrm{~A}}{0.85}=94 \mathrm{~W} \\
I_{d \varepsilon}=\frac{P_{\text {in }}}{V_{\text {in }}}=\frac{94 \mathrm{~W}}{20 \mathrm{~V}}=4.7 \mathrm{~A}
\end{gathered}
$$

Since the DC-DC converter is isolated, we can use a single 20 Vdc power supply to bias the voltage across the load and power the DC-DC converter. The circuit has been redrawn in Figure 3 to show the single power supply. Note that all circuit parameters remain the same.

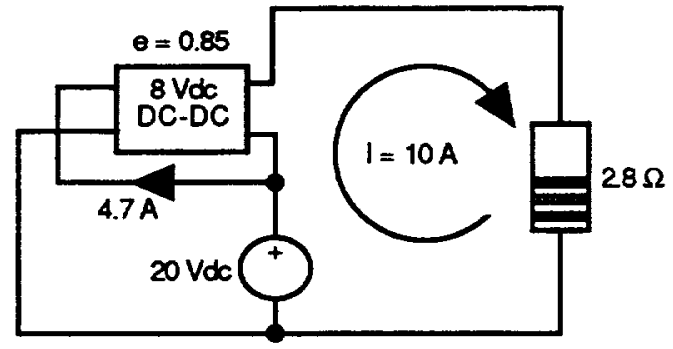

FIGURE 3 - USE SINGLE 2OV SUPPLY
Finally, Figure 3 is re-drawn as the standard SCBU configuration shown in Figure 4. The DC-DC converter is comnected in series with the 20 Vdc source, and the resulting output voltage is boosted by $8 \mathrm{Vdc}$, hence the name - Series Connected Boost Unit.

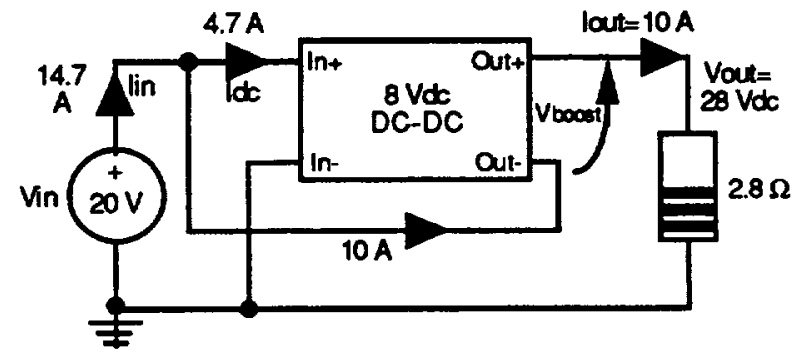

\section{FIGURE 4 - SERIES CONNECTED BOOST UNIT (SCBU)}

The benefits of the SCBU are clear once we analyze the circuit and examine the steady-state characteristics of the converter.

\section{SCBU CHARACTERISTICS}

Using an isolating DC-DC converter to provide a boost voltage above an input voltage can have a significant impact on many DC power systems. The SCBU topology offers the following advantages over conventional DC-DC boost converters:

1) High efficiency $(94 \%-98 \%)$

2) High power density $(>1,000 \mathrm{~W} / \mathrm{kg})$

3) Inherent fault tolerance

4) Easily adapted for positive ground systems, and

5) Can make use of relatively inexpensive commercial power supplies.

\section{Hlah Efflelency}

The SCBU benefits from high end-to-end efficiency because it only processes a portion of the power delivered. Efficiencies of $94 \%$ to $98 \%$ have been measured in the lab on a variety of SCBUs. These high efficiencies are possible with nominally efficient DC-DC converters (75-85\%) allowing designers to easily develop high efficiency components using low-cost, commercial parts.

In the circuit shown in Figure 4, a typical DC-DC converter with an efficiency of $85 \%$ is being used in the SCBU configuration. The efficiency of the SCBU can be calculated from the circuit parameters as:

$$
e_{\text {scbu }}=\frac{P_{\text {out }}}{P_{\text {in }}}=\frac{28 \mathrm{~V} \cdot 10 \mathrm{~A}}{20 \mathrm{~V} \cdot 14.7 \mathrm{~A}}=\frac{280 \mathrm{~W}}{294 \mathrm{~W}}=95.2 \%
$$

A general-purpose equation for the efficiency of a series connected boost unit can be derived from the SCBU circuit shown in Figure 4. The efficiency is calculated as:

$$
e_{\text {scbu }}=\frac{P_{\text {out }}}{P_{\text {in }}}=\frac{V_{\text {out }} \bullet I_{\text {out }}}{V_{\text {in }} \cdot I_{\text {in }}}
$$


where $V_{\text {out }}$ can be substituted by:

$$
V_{\text {out }}=V_{\text {in }}+V_{\text {boost }}
$$

$I_{\text {in }}$ is equal to the sum of the bypass current and the DC-DC converter input current, $\mathrm{I}_{d c}$. Since the bypass current is equal to the output current, Iour:

$$
I_{\text {in }}=I_{\text {out }}+I_{d c}
$$

As shown before, the DC-DC converter input current can be calculated from the output power, $P_{d c}$ :

$$
\begin{gathered}
P_{d c}=V_{\text {boost }} \bullet I_{\text {out }} \\
I_{d c}=\frac{P_{\text {in }}}{V_{\text {in }}}=\frac{P_{d c}}{e_{d c} \bullet V_{\text {in }}}=\frac{V_{\text {boost }} \bullet I_{\text {out }}}{e_{d c} \bullet V_{\text {in }}}
\end{gathered}
$$

Substituting [4] into [3] and simplifying results in:

$$
I_{\text {in }}=I_{o m u}\left(1+\frac{V_{\text {boost }}}{e_{d c} \bullet V_{\text {in }}}\right)
$$

Substituting [2] and [5] into [1] results in the simplified equation for the efficiency of the SCBU:

$$
e_{\text {scbu }}=\frac{V_{\text {in }}+V_{\text {boost }}}{V_{\text {in }}+\frac{V_{\text {boast }}}{e_{d c}}}
$$

As mentioned earlier, the efficiency of the SCBU is only slightly affected by the efficiency of the DC-DC converter. The main factor is the difference between $V_{\text {in }}$ and $V_{\text {boos. }}$. As $V_{\text {boost }}$ increases in relation to $V_{i n}$ the more predominant $V_{b o o s}+e_{d c}$ becomes. This indicates that the DC-DC converter is processing more of the total power delivered, thereby reducing the efficiency of the SCBU.

The equation of $[6]$ has a few limitations. First, the boost voltage cannot equal zero and must be greater than the rectifier diode "on" voltage in the output of the DC-DC converter. This is to account for the diode conduction losses when the SCBU is "off", otherwise the efficiency would equal $100 \%$ as $V_{\text {book }}$ went to zero. Also, it must be recognized that the efficiency of the DC-DC converter, $e_{d e}$ is a complex function of output power, input voltage, and boost voltage. In most cases, an average efficiency value can be used since most DC-DC converters have relatively flat efficiency curves above $40 \%$ rated power.

\section{Hiah Power Denslity}

The amount of power controlled by the SCBU can be 2-5 times the power rating of the DC-DC converter, greatly increasing its power density. This is because only a portion of the power is being processed by the DC-DC converter. The amount gained depends on the output voltage desired $\left(V_{\text {out }}\right)$ and the rated output current of the DC-DC converter ( $\mathrm{L}_{\text {out }}$ ). Since the output current rating is a function of the maximum boost voltage and the DC-DC converter power rating, the power rating of the SCBU can be expressed as a function of $V_{\text {out }}$ $V_{\text {boont, }}$ and $\mathbf{P}_{\text {de. }}$.

$$
\begin{gathered}
P_{\text {scbu }}=I_{\text {out }} \cdot V_{\text {out }} \\
I_{\text {out }}=\frac{P_{d c}}{V_{\text {boast }}(\max )} \\
P_{\text {scbut }}=\frac{V_{\text {out }}}{V_{\text {boost }}(\max )} \bullet P_{d c}
\end{gathered}
$$

The output current rating of the DC-DC converter limits the load current of the SCBU. Increasing this value will increase the power rating of the SCBU. Or, as shown in [7], the power rating of the SCBU can be maximized by minimizing the DC-DC converter boost voltage. Using Figure 4 as an example, an 80 Watt, 8 Vdc converter controlling a 28 Vde bus results in a power processing capability of 280 Watts - a $250 \%$ increase in power density.

$$
P_{s c b u}=\frac{28 V d c}{8 V d c} \cdot 80 W=280 W
$$

Larger gains are possible when considering higher bus voltages. In a recent program, a nominal 120 Vdc bus was regulated using a $1 \mathrm{~kW}, 28$ Vde converter. The resulting SCBU was able to process $4.25 \mathrm{~kW}$, an increase of $325 \%$ (Button and Baez, 1995).

In the unusual case when $V_{\text {ort }}$ is not required to be fixed, a DC-DC converter in the SCBU configuration can realize even higher power gains by maximizing the output voltage. By operating at the maximum input voltage, the output voltage will be maximized resulting in higher power levels.

In the previous example an $80 \mathrm{~W}, 8$ Vdc converter was used to regulate a $28 \mathrm{Vdc}$ bus. Assuming that this converter had an input voltage range from 16 to $32 \mathrm{Vdc}$ (a 2:1 ratio) it could operate at input voltages up to $32 \mathrm{Vdc}$. The SCBU's output voltage would maximize at $40 \mathrm{Vdc}$ at the rated current of $10 \mathrm{~A}$ resulting in a power level of $400 \mathrm{~W}$, an increase of $400 \%$.

It is clear that the power processing capabilities of an SCBU are significantly greater than conventional DC-DC converters. With only small increases in package size and weight due to the external control circuitry, the power density of an off-theshelf converter can easily be increased $100 \%$ to $400 \%$. Therefore, the power processing hardware will be much smaller and lighter than conventional converters.

\section{Inherent Fault Tolerance}

In many spacecraft power systems, a failure of the power processing hardware can result in complete loss of power and loss of mission. Since this hardware is so critical, fault tolerance requirements usually dictate an $\mathrm{N}+1$ redundancy scheme requiring extra hardware being flown as on-line backups in case of failure. This requirement can be particularly 
burdensome on amall spacecraft which may only require one power processing converter. Requiring $N+1$ redundancy doubles the size and weight of the power conversion hardware.

The SCBU topology can help to eliminate the need for $\mathrm{N}+1$ redundancy due to the inherent fault tolerance built into the design. In most DC-DC converters the input switching bridge is the most likely to fail. However, in the SCBU configuration, a failure of the DC-DC converter will not prevent power delivery to the main bus due to the series connection. Raw solar array power will be available allowing emergency operation of the satellite. This feature may be sufficient in meeting the spacecraft's fault tolerance specifications.

Further fault tolerance is provided by fusing the DC-DC converter input. This prevents a fault on the DC-DC converter input switching bridge from shorting the source. This fuse must be sized above the maximum DC-DC converter input current expected, but below the current limited source (such as a solar array). This will ensure that the source can generate sufficient current to open the fuse should a fault occur.

\section{Positive Ground Configuration}

The SCBU technology also allows the spacecraft designer the option of implementing a positive ground power system. A positive ground power system can be very effective in reducing the build-up of damaging plasma on high voltage solar arrays (Hickman, 1995).

All isolated DC-DC converters must include isolated voltage control circuits and gate drive circuits. The SCBU technology can take advantage of these isolated controls and be easily modified for a positive ground configuration. The positive ground topology is shown in Figure 5 .

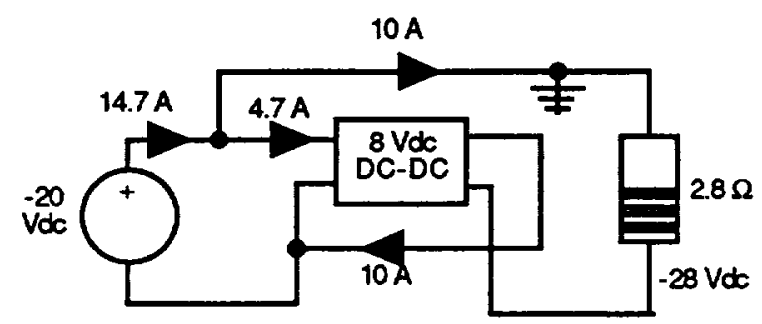

\section{FIGURE 5 - SCBU POSITIVE GROUND CONFIGURATION}

Instead of connecting Out- to Int as is shown in Figure 4, the positive ground topology connects Outt to In-. This allows the power supply's high side to be common with the load's high side allowing the positive ground comnection.

The positive ground topology has been demonstrated in a test bed development program at NASA Lewis. A $1 \mathrm{~kW} \mathrm{DC-}$ DC converter was modified for use in a $4.5 \mathrm{~kW}$ positive ground power system for a Solar Electric Propulsion spacecraft (Button and Baez, 1995).

\section{Commerclal DC-DC Converters}

The SCBU technology uses isolated DC-DC buck converters to control the amount of boost added to an input voltage. These DC-DC converters are readily available from several manufacturers in various quality levels (industrial, military, and flight qualified). Although they are not optimized for efficiency, it was shown earlier that the efficiency of the DC-DC converter is only a small factor in the SCBU efficiency. Using the SCBU technology, a very high efficiency converter can be built using inexpensive commercial DC-DC converter.

\section{SCBU Limitations}

Of course, all these SCBU benefits do not come free. There are three limitations that a power system must meet to take full advantage of the SCBU topology:

1) The SCBU is a boost converter and requires that the output voltage be greater than or equal to the input voltage at all times,

2) Galvanic isolation must not be required between input and output circuits, and

3) The input voltage source has a limited voltage range requiring only a small percentage $(<50 \%)$ of voltage boost.

Many power systems already meet these criteria. Spacecraft photovoltaic systems are an excellent example. A photovoltaic array can be sized during construction such that its output voltage is below the bus voltage. Galvanic isolation between the array and power bus is typically not a requirement in such systems. In addition, the solar array I-V curve is such that almost all power points can be reached over a small voltage range, requiring a small boost ratio.

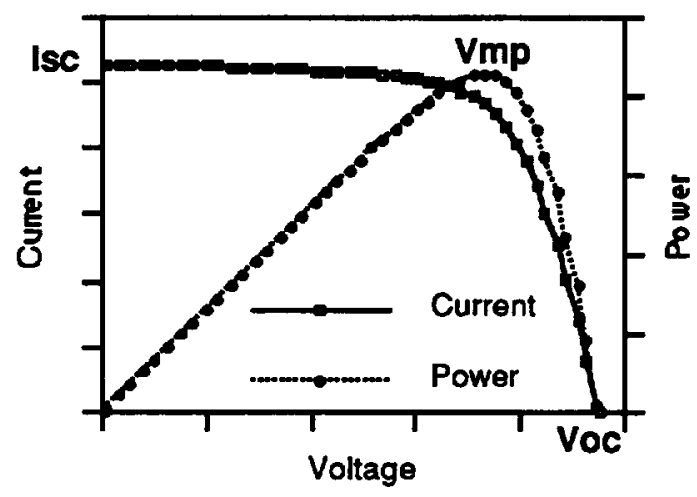

FIGURE 6 - SOLAR ARRAY I-V AND P-V CURVES

A solar array I-V and P-V curve is shown in Figure 6. By forcing the array to operate on the voltage leg (between $V_{m}$ and $V_{\infty}$ ), all power points can be reached in a relatively small voltage range.

Other systems that can benefit from the SCBU technology all have the same common features - the need for a regulated DC voltage from an unregulated DC source that has a limited voltage range. Some of these other applications include:

High power DC systems. DC systems requiring tight voltage regulation at the load can use the SCBU to efficiently boost the voltage at the load to compensate for line loss.

Thermionic diode power systems. Thermionic diodes are currently being developed as an electrical power source for orbital transfer vehicles. These diodes have distinct I-V curves with limited voltage ranges for the power levels required (Kimnach, 1996).

Battery output voltage regulators. SCBUs can be used to deliver fixed voltages as the battery voltage droops during discharge. 


\section{SCBU Deslan Considerations}

Selection of the DC-DC converter to be used in the SCBU configuration is important. There are a number of key requirements that must be met.

Voltage and Current Sizing. The DC-DC converter must be properly sized for the application. The system must be analyzed to determine the maximum input voltage range over the life of the spacecraft. This maximum boost voltage will determine the voltage rating of the DC-DC converter. Next, the spacecraft load is analyzed to determine the maximum current rating and low bus voltage. This value will determine the output current rating of the DC-DC converter.

Isolation. The DC-DC converter used in the SCBU must be a transformer isolated converter. This is required so that the series connection (between In+ and Out-) does not result in a short circuit. Also, the output stage must use a center-tapped transformer to prevent saturation due to the bypass current.

Output Voltage Regulation. The DC-DC converter must have some means of controlling its output voltage. Many manufacturers provide either external voltage sense inputs and/or output voltage trim inputs to control the output voltage.

The external voltage sense inputs are normally used to compensate for voltage drops down long cable lengths. These external sense inputs have a very high gain which can result in a control signal range of a few millivolts. Output voltage trim inputs (if available) can also be used to control the output voltage. The voltage trim input usually ranges from 4-10 Vdc and is more susceptible to noise than the voltage sense inputs.

SCBU Control Circuits. All SCBUs require added circuitry to provide: voltage regulation, current regulation, telemetry, and on-off control. These circuits require only a few op-amps and generally less than $1 \mathrm{~W}$ of power. The only difficulty is that the DC-DC converter control signal must be referenced to the output minus (Out-). This generally requires that an isolating amplifier be used to drive the DC-DC converter.

\section{PHOTOVOLTAIC ARRAY REGULATOR MODULE}

In designing electric power systems for new spacecraft, it has become clear that there are many similarities in their requirements. Most generate their power using photovoltaic solar arrays, store energy in batteries for use during eclipse periods, and require only minimal voltage regulation of the power distribution bus.

In the past, all new spacecraft began by custom designing the power management and distribution (PMAD) system to meet their spacecraft's specific mission requirements. These custom systems required long development times and were expensive to design, build, and test. The goal of the Photovoltaic Array Regulator is to develop a set of pre-engineered modules that can be combined to meet a wide range of future spacecraft requirements. These modules can significantly lower the development times and costs associated with spacecraft electric power systems. The key to developing a modular system is to identify those features which will be required for every mission and incorporate them in the modular design.

\section{PMAD System Functional Requirements}

The power management and distribution (PMAD) system on a typical satellite is expected to act as the "electric utility" providing regulated power to the spacecraft systems and scientific payloads. This system has four major functions to perform in any spacecraft:

Regulate the solar array power. The solar array must be regulated to ensure proper battery charging and to prevent the system load from "collapsing" the array voltage. The solar array power will vary greatly during the life of the mission and even during a single orbit. It is the function of the PMAD system to provide some measure of regulation. Regulation of the solar array can take many forms.

First and foremost is the need to regulate the battery charge current during insolation. Too little charge current could result in an inoperative system after several orbits, and too much charge current can overheat the battery and reduce its expected lifetime. An output voltage limit is also included to prevent battery overvoltage damage.

Bus voltage regulation is accomplished by the battery. Many spacecraft loads convert the distribution voltage (typically $28 \mathrm{Vdc}$ ) to lower useable voltages using small DCDC converters. These typically have wide input voltage ranges which can allow the distribution bus voltage to vary over a specified range. This range is usually well within the battery voltage range from full charge to minimum depth of discharge, obviating the need for battery voltage regulation.

Finally, solar array regulation may also need to incorporate a peak power tracking function. Since the solar array will be operated on the voltage leg of the I-V curve, it is possible to "collapse" the array by overloading the system with constant power loads. Any control circuit which attempts to moet a battery charge current setpoint during periods of reduced input power will cause the array to collapse by commanding too high a boost voltage. A peak power tracking circuit will override the battery charge current regulator and prevent the array from collapsing, while providing the maximum power available.

Provide load fault protection. The spacecraft PMAD system must be able to isolate load faults. This function requires a channelized approach to power distribution. The fault isolation function can be as simple as including fuses to permanently isolate misbehaving loads, or as complicated as using current limiting switches. The complexity of the fault protection used will be determined by the spacecraft requirements.

Provide housekeeping power for the PMAD hardware. All PMAD hardware requires electrical power to deliver electrical power - a seemingly "catch 22 " scenario. However, a properly designed PMAD system will be able to startup from either battery power following launch, or from raw solar array power should the battery system fail. Also, the housekeeping power supplies are usually required to be fault tolerant due to their critical function.

Communicate PMAD health to the spacecraft. Finally, the PMAD system must be able to communicate with the spacecraft to accept new operating parameters and report general PMAD status and health. Each component includes a data interface unit (DIU) and the accompanying telemetry circuits to provide PMAD system status to the spacecraft and to other PMAD hardware. 


\section{A Modular PMAD Desian}

A block diagram of a proposed modular PMAD system based on the SCBU technology is shown in Figure 7. Besides the power generation and storage systems, the PMAD system consists of three major components. Each component contains a number of functions necessary to meet the PMAD system requirements outlined above. Also, the system has been designed to be modular, that is, a wide range of spacecraft missions and power levels can be met using this hardware.

The Power Input Unit is used to bus all solar array sources necessary to power the channel. Included in this unit is the solar array telemetry and a peak power tracker whose main function is to detect peak power point crossings. The power processing hardware (SCBUs) is then notified through the Data Interface Units (DIU) to reduce the battery charge current.

The SCBU Slice(s) are pre-engineered power processing units used to provide solar array regulation. These modular components contain all the circuitry necessary to operate independently and/or in parallel with other units. Two power levels are currently being developed for each slice - a $250 \mathrm{~W}$ unit and a $500 \mathrm{~W}$ unit. By paralleling several slices, spacecraft requiring up to $2 \mathrm{~kW}$ of regulation can be accommodated with these SCBU slices.

The SCBU slices will incorporate small Data Interface Units to provide telemetry and health monitoring to the spacecraft computer. They will also be used to set the various operating parameters which will be determined by the Power Input Unit (peak power tracking) and the Power Distribution Unit (battery charge rate).

The Power Distribution Unit serves several purposes. It includes the main distribution bus, the battery charge management circuitry, the spacecraft single point ground, and the PMAD housekeeping power supplies.

The main distribution bus must provide power to all spacecraft loads through distribution switches and/or fuses depending on the spacecraft requirements. Use of modular fault protection switches and a family of fuse sizes will simplify the design of the power distribution unit.

The PDU connects the battery to the main bus through fault protection fuses. These fuses, which are greatly oversized, are the last line of defense should a fault occur on the main bus. Battery health monitoring is provided through the PDU and includes: battery current, battery voltage, cell voltage measurements, and cell temperature data. Specialized microprocessors will be used to determine the battery state of charge, thereby off-lowding this function from the main spacecraft computer.

\section{CONCLUSIONS}

It is clear that the spacecraft industry must incorporate modular systems to be competitive in the 21 st centary. A modular PMAD system based on the SCBU technology has shown promise in meeting the needs of a wide variety of missions. The SCBU has miny advantages over other regulators. It is very efficient, has very high power density, and benefits from an inherent fault tolerance. These qualities all add up to smaller, lightweight spacecraft which can be developed quickly and economically.

\section{ACKNOWLEDGEMENTS}

The author would like to acknowledge Mr. Raymond Beach and Mr. Andrew Brush for their innovation of the Series Connected Boost Unit in spacecraft power systems.

\section{REFERENCES}

Baez, A.N., et. al, 1996, "The Small Spacecraft Technology Initiative Photovoltaic Regulator Kit Experiment (PRKE)", Proceedings, 31st Intersociety Energy Conversion Engineering Conference, Washington, D.C.

Button, R.M. and Baez, A.N., 1995, "A Modular Electric Power System Test Bed for Small Spacecraft," NASA Technical Memorandum \#106812, NASA Lewis Research Center, Cleveland, $\mathrm{OH}$.

Hickman, J.M., 1994, "Solar Electric Propulsion for Magnetospheric Mapping," Proceedings, 30th AlAA/ASME/ SAE/ASEE Joint Propulsion Conference.

Kimnach, G.L., 1996, "Design of a Power Management and Distribution System for a Thermionic Diode Powered Spacecraft," Proceedings, 31st Intersociety Energy Conversion Engineering Conference, Washington, D.C.

Beach, R.F. and Brush A.S., 1993, "Series Connected Converter for Control of Multi-Bus Spacecraft Power Utility," NASA Disclosure of Invention \#LEW15918-1C, NASA Lewis Research Center, Cleveland, OH.

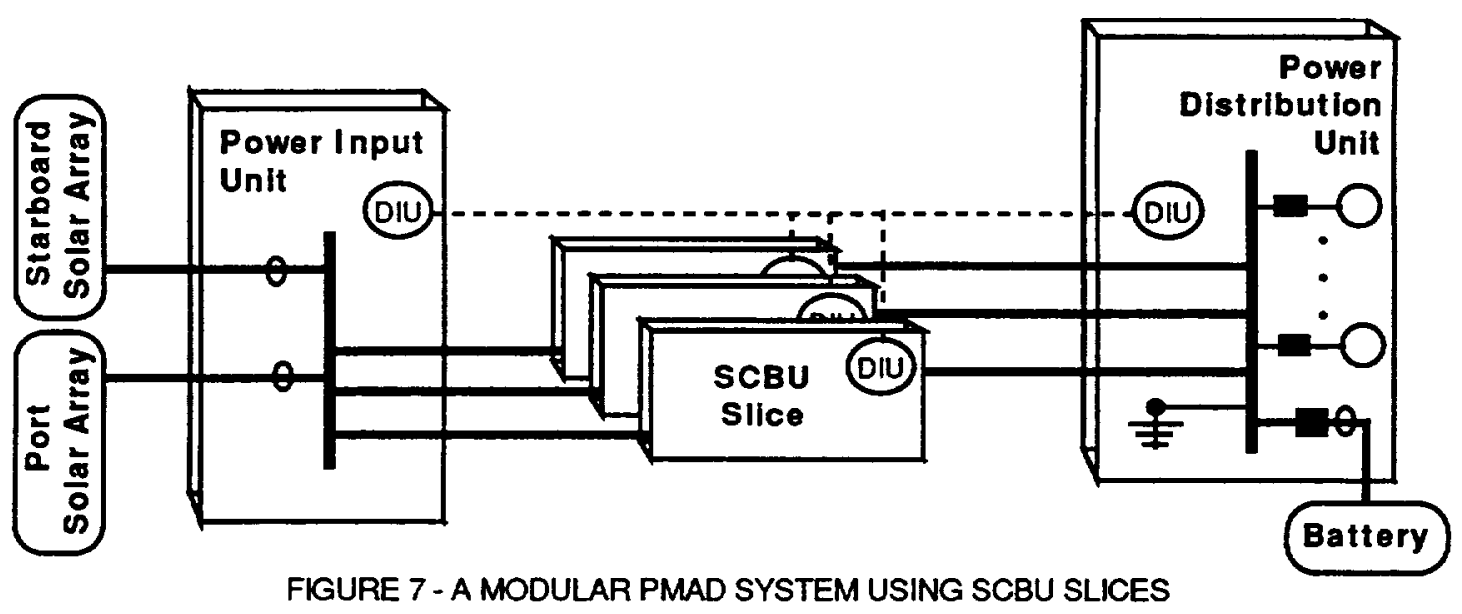



Public reporting burden for this collection of hrormation is estimated to averege 1 hour per response, Including the time for neviowing hintructions, searching exiating data sources,

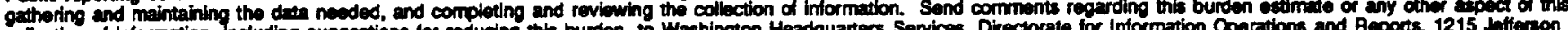
collection of Information, Including sugpestions for reducing thits burden, to Washington Headquarters Services, Directorate lor Intormation Operations and Reports, 1215 Leller

\begin{tabular}{|l|l|l}
\hline 1. AGENCY USE ONLY (Leavo blank) & $\begin{array}{c}\text { 2. REPOFT DATE } \\
\text { August } 1996\end{array}$ & $\begin{array}{r}\text { 3. REPOFT TYPE AND DATES COVEAED } \\
\text { Technical Memorandum }\end{array}$
\end{tabular}

4. TILE AND SUBTIRE 5. FUNDING NUMBERS

An Advanced Photovoltaic Array Regulator Module

6. AUTHOR(S)

WU-233-1A-1C

Robert M. Button

7. PERFORINGG ORGANIZATION NAME(S) AND ADDRESS(ES)

National Aeronautics and Space Administration

Lewis Research Center

Cleveland, Ohio 44135-3191

B. PERFORIMNG ORGANIZATION REPORT NUMBEA

E-10391

9. SPONSORINGMONUTOPANG AGENCY NAME(S) AND ADDRESS(ES)

National Aeronautics and Space Administration

Washington, D.C. 20546-0001

10. SPONSORINGMONITORING AGENCY REPORT NUMBER

NASA TM-107304

IECEC-96424

\section{SUPPLENENTARY NOTES}

Prepared for the 31st Intersociety Energy Conversion Engineering Conference cosponsored by IEEE, AIChE, ANS, SAE, AIAA, and ASME, Washington, D.C., August 11-16, 1996. Responsible person, Robert M. Button, organization code 5450, (216) 433-8010.

\begin{tabular}{l|l|l} 
12a. DISTRIBUTONVAVALABILTY STATENENT & 12b. DISTRIBUTION CODE
\end{tabular}

Unclassified - Unlimited

Subject Category 20

This publication is available from the NASA Center for AeroSpace Information, (301) 621-0390.

13. ABSTRACT (Maximum 200 words)

Current trends in satellite design are focused on developing small, reliable, and inexpensive spacecraft. To that end, a modular power management and distribution system is proposed which will help transition the aerospace industry towards an assembly line approach to building spacecraft. The modular system is based on an innovative DC voltage boost converter called the Series Connected Boost Unit (SCBU). The SCBU uses any isolating DC-DC converter and adds a unique series connection. This simple modification provides the SCBU topology with many advantages over existing boost converters. Efficiencies of $94-98 \%$, power densities above $1,000 \mathrm{~W} / \mathrm{kg}$, and inherent fault tolerance are just a few of the characteristics presented. Limitations of the SCBU technology are presented, and it is shown that the SCBU makes an ideal photovoltaic array regulator. A set of photovoltaic power system requirements are presented that can be applied to almost any low Earth orbit satellite. Finally, a modular design based on the series connected boost unit is outlined and functional descriptions of the components are given.

14. SUBJECT TEAMS

Power converters; Spacecraft electronic equipment; Voltage converters; DC to DC

17. SECUATYY CLASSIFICATION OF REPORT Unclassified

18. SECURTY CLASSIFICATION
OF THIS PAGE
Unclassified

Unclassified

19. SECURITY CLASSIFICATION
OF ABSTRACT
Unclassified




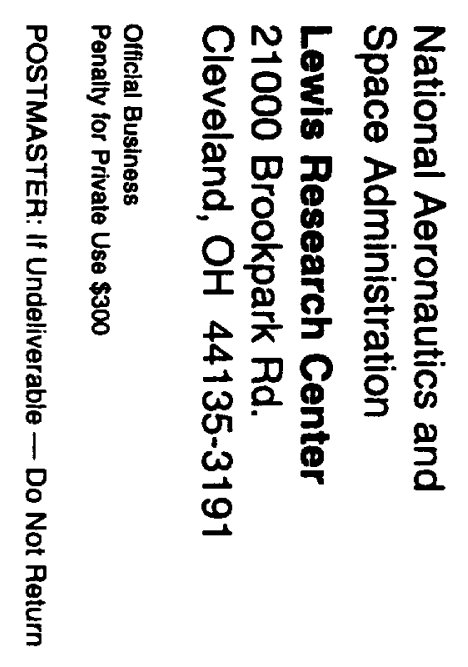

